\title{
The metal tolerance profile of Thlaspi goesingense is mimicked in Arabidopsis thaliana heterologously expressing serine acetyl-transferase
} John L Freeman ${ }^{* 1,2}$ and David E Salt ${ }^{1}$

Address: ${ }^{1}$ Center for Plant Environmental Stress Physiology, Purdue University, Horticulture and Landscape Architecture Department. West Lafayette, Indiana 47907, USA and ${ }^{2}$ Biology Department, Colorado State University, Program in Molecular Plant Biology, Fort Collins, Colorado 80523, USA

Email: John L Freeman* - John.Freeman@ColoState.edu; David E Salt - DSalt@Purdue.edu

* Corresponding author

Published: 28 November 2007

BMC Plant Biology 2007, 7:63 doi:10.1 I86/147|-2229-7-63
Received: 6 February 2007

Accepted: 28 November 2007

This article is available from: http://www.biomedcentral.com/147I-2229/7/63

(C) 2007 Freeman and Salt; licensee BioMed Central Ltd.

This is an Open Access article distributed under the terms of the Creative Commons Attribution License (http://creativecommons.org/licenses/by/2.0), which permits unrestricted use, distribution, and reproduction in any medium, provided the original work is properly cited.

\begin{abstract}
Background: The Ni hyperaccumulator Thlaspi goesingense is tolerant to $\mathrm{Ni} \cong \mathrm{Zn}, \cong \mathrm{Co}$ and slightly resistant to $>\mathrm{Cd}$. We previously observed that elevated glutathione, driven by constitutive activation of serine acetyltransferase (SAT), plays a role in the Ni tolerance of $T$. goesingense.

Results: Here we show that the elevated shoot concentration of glutathione, previously shown to cause elevated $\mathrm{Ni}$ tolerance in Arabidopsis thaliana heterologously expressing $T$. goesingense mitochondrial serine acetyltransferase (SATm), also causes tolerance to Co and $\mathrm{Zn}$ while slightly enhancing resistance to $\mathrm{Cd}$. The level of tolerance afforded to each metal is ranked $\mathrm{Ni} \cong \mathrm{Co},>\mathrm{Zn}$ $>\mathrm{Cd}$. The $\mathrm{Ni} \cong \mathrm{Co},>\mathrm{Zn}$ tolerances are positively correlated with both the accumulation of glutathione (GSH) and the ability to resist the oxidative damage induced by these different metals. Based on the relative concentrations of each metal used a relatively low level of resistance to $\mathrm{Cd}$ was observed in both $T$. goesingense and TgSATm expressing lines and $\mathrm{Cd}$ resistance was least correlated to GSH accumulation.

Conclusion: Such data supports the conclusion that elevated glutathione levels, driven by constitutively enhanced SAT activity in the hyperaccumulator $T$. goesingense, plays an important role in the $\mathrm{Ni}, \mathrm{Co}$ and $\mathrm{Zn}$ tolerance of this and other Thlaspi species. The hyper-activation of $\mathrm{S}$ assimilation through SAT is an excellent strategy for engineering enhanced metal tolerance in transgenic plants potentially used for phytoremediation.
\end{abstract}

\section{Background}

The natural phenomenon of heavy metal tolerance in specialized hyperaccumulator plants has sparked the interests of plant physiologists, plant ecologists and evolutionary biologists for over 50 years [1]. The first investigation into metal tolerance present in plant species was by evolutionary ecologists studying primary successionary species that can colonize areas of newly created metaliferous soils such as mine spoils [2]. In recent years, the understanding of the physiological basis of metal(loid) tolerance has increased due to the development of new analytical and molecular technologies $[3,4]$. Our research has focused on investigating the physiology of metal tolerance in metal hyperaccumulating plants, which are clearly hyper-toler- 
ant to the metals they hyperaccumulate. However, certain Thlaspi hyperaccumulator species also display co-tolerance to metals not necessarily present in their native habitat [5]. Metal tolerance and metal hyperaccumulation are different but inter-related phenomena, and have been extensively reviewed $[1,4,6,7]$. In metal hyperaccumulators the genetic determinants of metal tolerance and accumulation segregate independently, confirming that different genes are responsible for these phenomena $[8,9]$. Additionally, transcriptional profiling has opened a window into the identity of the genetic changes driving metal hyperaccumulation, by uncovering sets of coordinated gene expression differences that likely control uptake, accumulation and tolerance in hyperaccumulatorsb [1012]

Metal toxicity in plants is often caused by the production of reactive oxygen species (ROS) [13-17]. Reduced glutathione (GSH) a strong antioxidant can directly reduce some active oxygen species [18] and also provides the reducing equivalents for the ascorbate-GSH antioxidant cycle [16]. Previous biochemical comparisons between $T$. goesingense and the closely related non-accumulator $A$. thaliana, revealed that in $T$. goesingense constitutively elevated GSH levels, driven by higher activity of the enzyme serine acetyltransferase (SAT), are partly responsible for the elevated Ni tolerance observed in this species [19]. The heterologous expression of T. goesingense SATm in A. thaliana was observed to significantly increase GSH levels, mimicking those found in $T$. goesingense and consequently conferred increased resistance to $\mathrm{Ni}$ [19]. Elevated shoot levels of $\mathrm{O}$-acetyl-L-serine, the product of SAT and a precursor for glutathione biosynthesis has recently been show to also correlate with $\mathrm{Ni} / \mathrm{Zn}$ hyperaccumulation ability across numerous genera in the Brassicaceae family [20].

SAT and its product OAS have been shown to control the enzymes responsible for sulfate reduction and cysteine biosynthesis in plants [21]. The production of OAS and cysteine also limit the overall rate of glutathione biosynthesis and the maintenance of an elevated glutathione pool [22,23]. Sulfur assimilatory mechanisms and the production of GSH are known to be highly induced by both heavy metal treatments and oxidative stress [24,25]. While oxidative stress tolerances in plants have been increased using transgenic methods to produce elevated levels of OAS, Cys and GSH [26-28], relatively little was known about the effect similar increases might have on the metal tolerance of plants. Increases in these metabolites, through over expression of specific enzymes involved in their biosynthesis, were found to result in $\mathrm{Ni}$ tolerance in A. thaliana [19] and Cd tolerance in B. juncea [29].
Here we report our observations of the role of GSH in conferring multiple metal tolerances in A. thaliana heterologously expressing TgSATm. These results demonstrate intriguing similarities with the metal tolerance profile observed in the Ni hyperaccumulator T. goesingense with contains naturally enhanced GSH levels. Such data supports our conclusion that constitutively elevated GSH plays an important role in the multi-metal $(\mathrm{Ni}, \mathrm{Zn}$ and $\mathrm{Co}$ ), tolerance and $\mathrm{Cd}$ resistance observed in $T$. goesingense and $A$. thaliana heterologously expressing TgSATm.

\section{Results \\ Metal tolerance profile of the Ni hyperaccumulator $\mathbf{T}$. goesingense}

Total GSH in mature T. goesingense and A. thaliana (Wassilewskija) was previously measured and found to be $412.5 \pm 80$ and $268.86 \pm 48.1 \mathrm{nmol} \mathrm{g}^{-1}$ fwt respectively [19]. The tolerance of $T$. goesingense to various metals including $\mathrm{Ni}, \mathrm{Co}, \mathrm{Zn}$ and $\mathrm{Cd}$ was investigated by measuring root growth compared to the non-tolerant relative $A$. thaliana Wassilewskija (WS) (Fig. 1) of plants grown on solidified MS medium containing Ni, Co, Zn or Cd. When comparing the concentration of a metal required for a $50 \%$ inhibition of root growth or $\left(\mathrm{I}_{50}\right) T$. goesingense was found to be the most tolerant to $\mathrm{Ni} \cong \mathrm{Zn} \cong \mathrm{Co}$, with a low level of resistance to $\mathrm{Cd}$ (Table 1 ). The relative tolerance index (RTI) was calculated as the $\mathrm{I}_{50}\left[T\right.$. goesingense]// $\mathrm{I}_{50}[\mathrm{~A}$. thaliana]. By using the RTI as a comparative measure of tolerance $T$. goesingense was observed to have enhanced relative tolerance to $\mathrm{Ni} \cong \mathrm{Zn} \cong \mathrm{Co}$, with a low level of resistance to $\mathrm{Cd}$ when compared to $A$. thaliana (WS) (Table 1). To investigate how much of the metal tolerance observed in $T$. goesingense is due to increased resistance of oxidative damage we measured shoot lipid peroxidation in T. goesingense and A. thaliana after 8-days growth in the presence of Ni, Zn, Co or Cd (Fig. 2). We observed that relative to $A$. thaliana the hyperaccumulator $T$. goesingense contained significantly less peroxidized lipids after growth in the presence of $\mathrm{Ni}$, Co and $\mathrm{Zn}$, however no difference was observed after growth in the presence of $\mathrm{Cd}$.

\section{Metal tolerance profile of A. thaliana heterologously expressing $\mathbf{T}$. goesingense serine acetyl-transferase}

Previously, we reported that heterologous expression of $T$. goesingense SAT $\left(\mathrm{TgSAT}_{m}\right)$, leading to elevated shoot GSH levels, resulted in enhanced $\mathrm{Ni}$ tolerance of $A$. thaliana [19]. The total GSH present in TgSAT-m heterologous expressing lines, pooled from plates as young plants, was $($ S 4-9, $496 \pm 20),($ S 3-1, $369 \pm 5),($ S 5-4, $188 \pm 9)$ nmol $\mathrm{g}^{-1} \mathrm{Fwt}$, and represent the high, intermediate and low SAT expressors while the two empty vector controls with the same phenotype were (E 1-5, $172 \pm 9)$ and (E 4-5, $142 \pm$ 5) nmol g-1 Fwt [19]. In addition to the TgSATm Ni tolerance shown growing in the vertical plates (Fig. 3A, $30 \mathrm{~d}$ ), we also discovered metal tolerances to Co (Fig. 3B, $18 \mathrm{~d}$ ) 

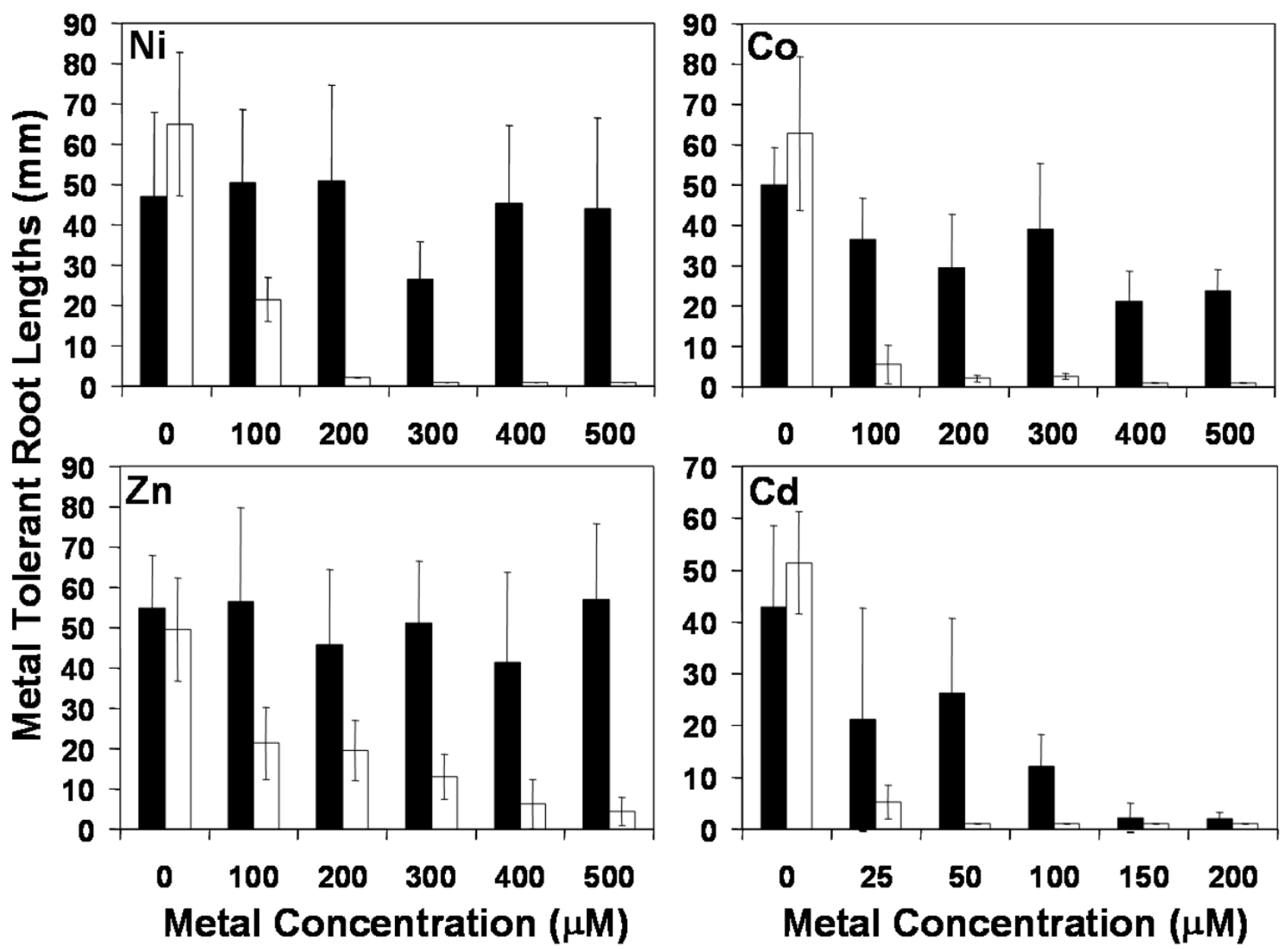

Figure I

Metal tolerance present in T. goesingense (black) compared to A. thaliana (white) measured as root growth in (mm) 18 days after imbibition, on $\mathrm{I} / 2$ strength $\mathrm{MS}$ medium containing $\mathrm{O}-500 \mu \mathrm{M}$ amounts of $\mathrm{Ni}\left(\mathrm{NO}_{3}\right)_{2}(\mathrm{Ni}), \mathrm{Co}\left(\mathrm{NO}_{3}\right)_{2}(\mathrm{Co}), \mathrm{Zn}\left(\mathrm{NO}_{3}\right)_{2}$ $(\mathrm{Zn})$ and $\mathrm{Cd}\left(\mathrm{NO}_{3}\right)_{2}(\mathbf{C d})$. ( $\mathrm{n}=6 \mathrm{~T}$. goesingense. and $A$. thaliana plants for each bar $\left.\pm \mathrm{SD}\right)$.

and to $\mathrm{Zn}$ (Fig. 3C, $18 \mathrm{~d}$ ) and resistance to Cd (Fig. 3D, 18 d). The Ni tolerance of TgSATm was previously quantified using a metal growth, zone of inhibition assay, on plates, [19] (Fig 4A Ni). Using the same disc assay here, we quantify that plants heterologously expressing $T g S A T_{m}$ are also tolerant to Co (Fig. 4B) and Zn (Fig. 4C), and show enhanced resistance to Cd (Fig. 4D). By using lines with measured levels of $T g S A T_{m}$ expression, enzyme activity and GSH accumulation [19], and multiple empty vector controls, quantitative data was obtained for the growth response to $\mathrm{Ni}, \mathrm{Co}, \mathrm{Zn}$ and $\mathrm{Cd}$ of high $\mathrm{S} 4-9$ (black), intermediate S 3-1 (grey) and low S 5-4(white) or non-expressing lines, empty vector E 1-5(striped), of $A$. thaliana transformed with $\mathrm{TgSAT}_{m}$. Though such an assay produces only a relative measurement of tolerance, quantified as the distance from a metal-soaked disc, it allows highly reproducible results and measurements of both tolerance and accumulation over a continuous gradient of metal concentrations. In this method we use different parameters to assess plant growth than just root lengths, including development of normal upright shoot cotyledons, secondary leaf formation, and formation of a root hook as the root bends on contact with the base of the Petri dish. Data is expressed as a percentage of the total number of seedlings in each ring around the metal soaked disc. This assay takes full advantage of the metal concentration gradient established as the metal diffuses from the disc, allowing resolution of differences in metal tolerance between lines and various metals. Based on estimations of shoot and root growth on both vertical plates and disk assay plates (Fig. 3 \&4), heterologous expression of $\mathrm{TgSAT}_{m}$ was observed to provide significant increases in tolerance to $\mathrm{Ni}$, Co and $\mathrm{Zn}$ along with a slight amount of $\mathrm{Cd}$ resistance. 


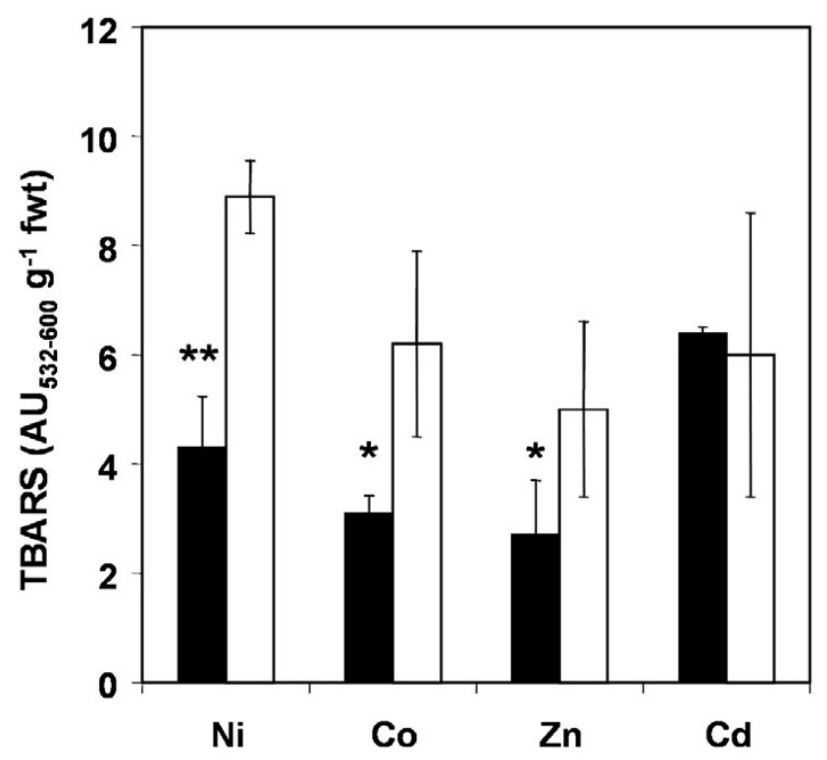

Figure 2

Shoot lipid peroxidation measured as TBARS in the hyperaccumulator $T$. goesingense (black) and the non accumulator $A$. thaliana (white) formed in response to each of the 4 different metal treatments after growth in normal media followed by transfer and growth on plates containing I/2 strength MS medium with I $25 \mu \mathrm{M} \mathrm{Ni}\left(\mathrm{NO}_{3}\right)_{2}, \mathrm{I} 25 \mu \mathrm{M}$ Co $\left(\mathrm{NO}_{3}\right)_{2}, \mathrm{I} 25$ $\mu \mathrm{M} \mathrm{Zn}\left(\mathrm{NO}_{3}\right)_{2}$, or $75 \mu \mathrm{MCd}\left(\mathrm{NO}_{3}\right)_{2}$ for a period of 8 days. Values represent difference in TBARS compared to growth on control media without added metals. Data represents averages $(n=4) \pm S D .\left({ }^{*}<<0.05 ; * * p<0.0\right.$ l, t-test)

Shoot material from the TgSATm lines and empty vector controls grown at $20 \mathrm{~mm}$ and $35 \mathrm{~mm}$ from the disc were harvested for ICPMS analysis to investigate the respective metal concentrations. Interestingly, although tolerance to $\mathrm{Ni}$, Co and $\mathrm{Zn}$ was increased in lines heterologously expressing $\operatorname{TgSAT}_{m}$, these tolerant lines had little or no increase in shoot accumulation of $\mathrm{Ni}$, Co or $\mathrm{Cd}$. The only exception to this was for $\mathrm{Zn}$, because both the highest ( $\mathrm{S}$ 4-9), and intermediate (S 3-1) SAT expressing and GSH accumulating TgSATm lines harvested from the $20 \mathrm{~mm}$

Table I: Metal concentration $(\mu \mathrm{M})$ which caused $50 \%$ inhibition of root growth $\left(1^{50}\right)$ for the different metals used on $T$. goesingense and $A$. thaliana followed by the relative comparative tolerance index of $T$. goesingense for different metals.

\begin{tabular}{ccccc}
\hline & $\begin{array}{c}\text { Nickel } \\
(\mu \mathrm{M})\end{array}$ & Cobalt & Zinc & Cadmium \\
\hline $\begin{array}{c}\text { Thlaspi goesingense } \\
\text { Arabidopsis thaliana } \\
\text { Comparative }\end{array}$ & $>500$ & 460 & $>500$ & 38 \\
$\begin{array}{c}\text { Tolerance Index (150 } \\
\text { Thlaspi//50 Arabidopsis) }\end{array}$ & & 56 & 98 & 13 \\
& & & & \\
\hline
\end{tabular}

ring had a 1.3-1.5 fold higher shoot $\mathrm{Zn}$ concentration $\left(8,936 \pm 760 \& 10,050 \pm 458 \mu \mathrm{g} \mathrm{Zn} \mathrm{g}^{-1}\right.$ Dwt respectively $)$ compared to the low (S 5-4) and non-expressing line (E $1-5)$ at $(6,704 \pm 656 \& 6,644 \pm 94 \mu \mathrm{g} \mathrm{Zn} \mathrm{g-1}$ Dwt respectively). While the tolerant SAT lines did not accumulate more metal than the others except for $\mathrm{Zn}$ the overall levels were all quite high, for $\mathrm{Ni}(\sim 1,200), \mathrm{Zn}(\sim 6,000-10,000)$, Co $(\sim 2,000)$ and Cd ( 2,000) $\mu \mathrm{g} \mathrm{g}^{-1}$ Dwt.

To determine if enhanced resistance to oxidative stress plays a role in the metal tolerances conferred by heterologous expression of $T g S A T_{m}$ we measured lipid peroxidation in shoots of plants after growth in the presence of toxic levels of $\mathrm{Ni}, \mathrm{Co}, \mathrm{Zn}$ and $\mathrm{Cd}$ (Fig. 5). These results demonstrate that under the conditions used growth in the presence of $\mathrm{Ni}$, Co and $\mathrm{Zn}$ produce greater lipid peroxidation than $\mathrm{Cd}$. They also show that lines with relatively strong expression of TgSATm (black bars), have the lowest levels of lipid peroxidation in plants grown in the presence of either $\mathrm{Ni}$, Co or $\mathrm{Zn}$. However, heterologous expression of TgSATm conferred no decrease in lipid peroxidation in Cd exposed plants, most likely because Cdinduced lipid peroxidation was low even in control lines (Fig. 5).

Heterologous expression of $T g S A T_{m}$ was also observed to increase resistance to hydrogen peroxide (Fig. 6). This assay measures the remaining chlorophyll content of leaf discs floated on various concentrations of hydrogen peroxide under high light. Both wild type and empty vector A. thaliana were used as controls and produced the same results, data for empty vector control is shown (Fig. 6). These results establish that heterologous expression of $\mathrm{TgSAT}_{m}$ also enhances tolerance to general oxidative stress, beyond that caused specifically by growth in the presence of the metals tested. Interestingly, the hyperaccumulator T. goesingense, which is known to have constitutively elevated SAT activity and accumulate elevated GSH [19], also showed significant tolerance to hydrogen peroxide treatments (Fig. 6).

\section{Association of GSH with tolerance to $\mathrm{Ni}, \mathrm{Co}, \mathrm{Zn}$ and enhanced resistance to $C \boldsymbol{d}$}

Heterologous expression of $T g S A T_{m}$ was previously shown to increase both shoot GSH levels and Ni tolerance (Freeman et al., 2004). We observe here that in addition to increased $\mathrm{Ni}$ tolerance, elevated GSH also leads to increased tolerance to the growth inhibitory effects of Co, $\mathrm{Zn}$ and a low level of resistance to $\mathrm{Cd}$. However, by comparing the magnitude of the tolerance to $\mathrm{Ni}, \mathrm{Co}, \mathrm{Zn}$, and $\mathrm{Cd}$ resistance conferred by heterologous expression of $\mathrm{TgSAT}_{m}$ with the concentration of shoot GSH, across lines with different levels of SAT expression, we established that the effectiveness of GSH in enhancing metal tolerance varies with the metal. The percent toxicity, scored for both 


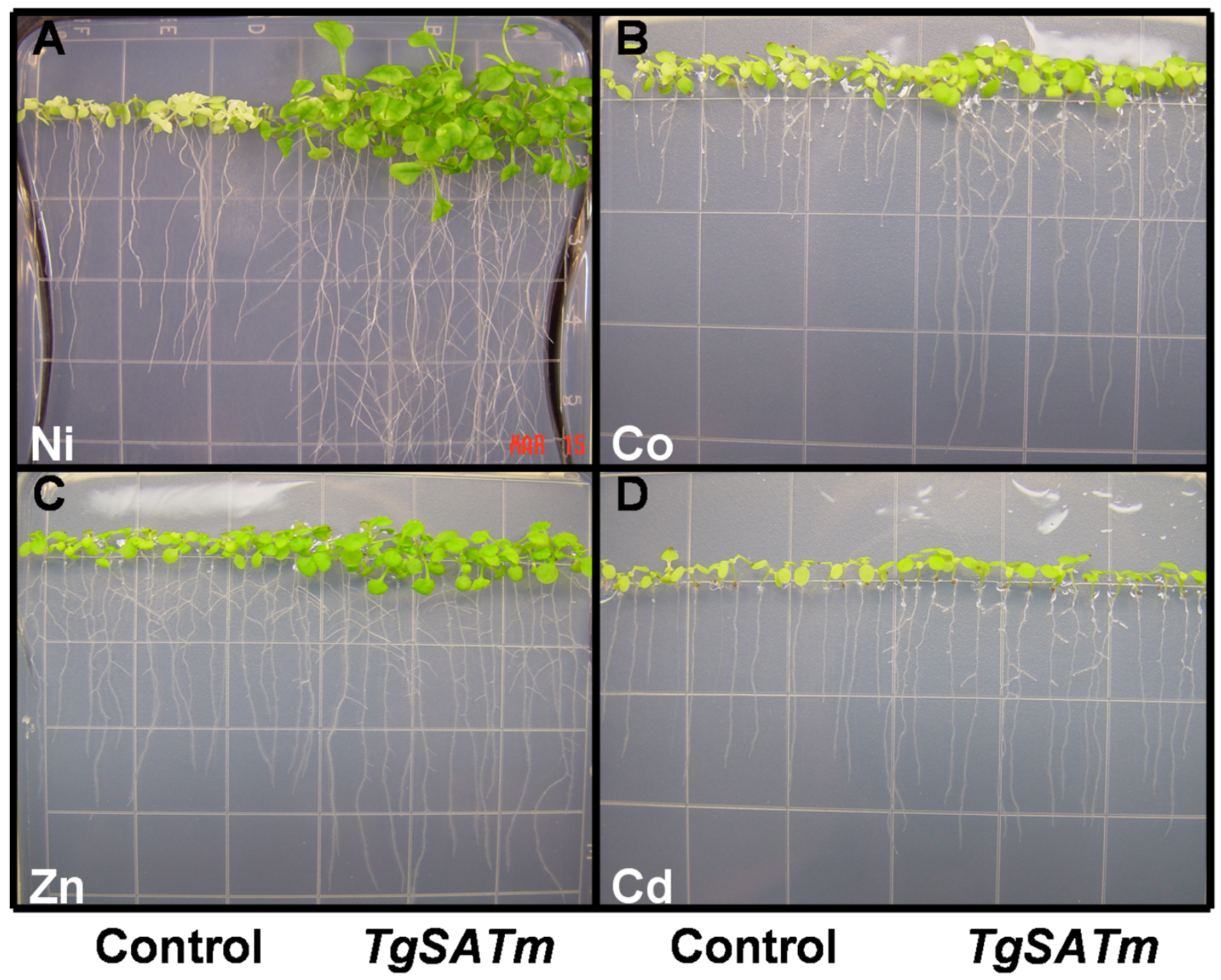

Figure 3

Vertical plates showing effect on metal tolerance of SAT ectopic expression in A. thaliana shoot tissue from homozygous T4 lines transformed with vector containing TgSAT-m (S 4-9) or empty vector (E I-5) control. Plants were grown together on I/2 strength MS upright agar plates containing $100 \mu \mathrm{M} \mathrm{Ni}\left(\mathrm{NO}_{3}\right)_{2}$ for 30 days from imbibition (A), plates containing $100 \mu \mathrm{M}$ Co $\left(\mathrm{NO}_{3}\right)_{2}$ for 18 days from imbibition $(\mathbf{B}), 120 \mathrm{uM} \mathrm{Zn}\left(\mathrm{NO}_{3}\right)_{2}$, 18 days from imbibition $(\mathbf{C})$, and $25 \mu \mathrm{M} \mathrm{Cd}\left(\mathrm{NO}_{3}\right)_{2} 18$ days from imbibition (D).

shoot and root, was calculated for each line and metal at the seedling ring, which had the maximum difference in tolerance when the highest SATm expressing line was compared to the control line. These tolerance values were plotted against the GSH synthesis capacity of each line, and the relationship was found to be linear, with increasing GSH conferring increasing metal tolerance to $\mathrm{Ni}$, Co, $\mathrm{Zn}$, and resistance to $\mathrm{Cd}$ (DNS). From the slope of these plots the metal tolerance vs GSH concentration value is obtained for each metal in both shoot and root (Fig. 7). The equivalent increase in shoot GSH concentrations was most effective at increasing shoot tolerance to $\mathrm{Ni}$ and $\mathrm{Co}$, followed closely by $\mathrm{Zn}$ then least effective was Cd resistance. GSH also caused elevated metal tolerances in roots to Co followed by $\mathrm{Ni}$ and $\mathrm{Zn}$, while $\mathrm{Cd}$ resistance in roots was least correlated to total GSH production. However, metal levels in the roots were not measured and Cd may have been much higher here, as $\mathrm{Cd}$ is known to accumulate in roots.

\section{Discussion}

The T. goesingense mitochondrial version of SAT was chosen for use in this study over that of the chloroplast and the cytosolic versions because it conveyed a high level of 
A
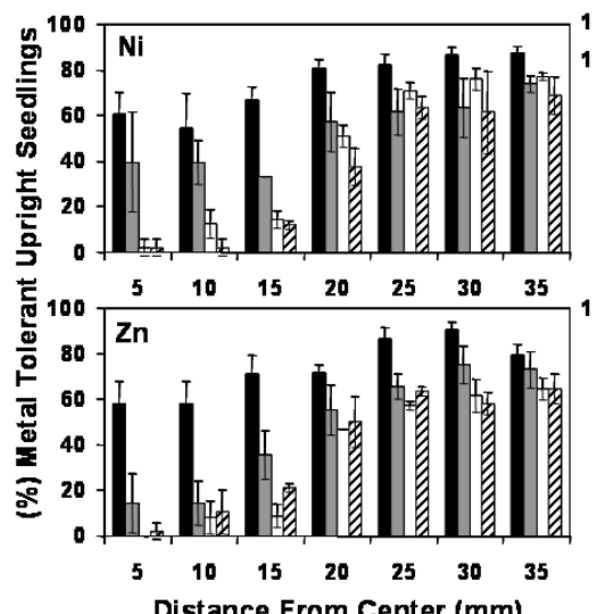

B
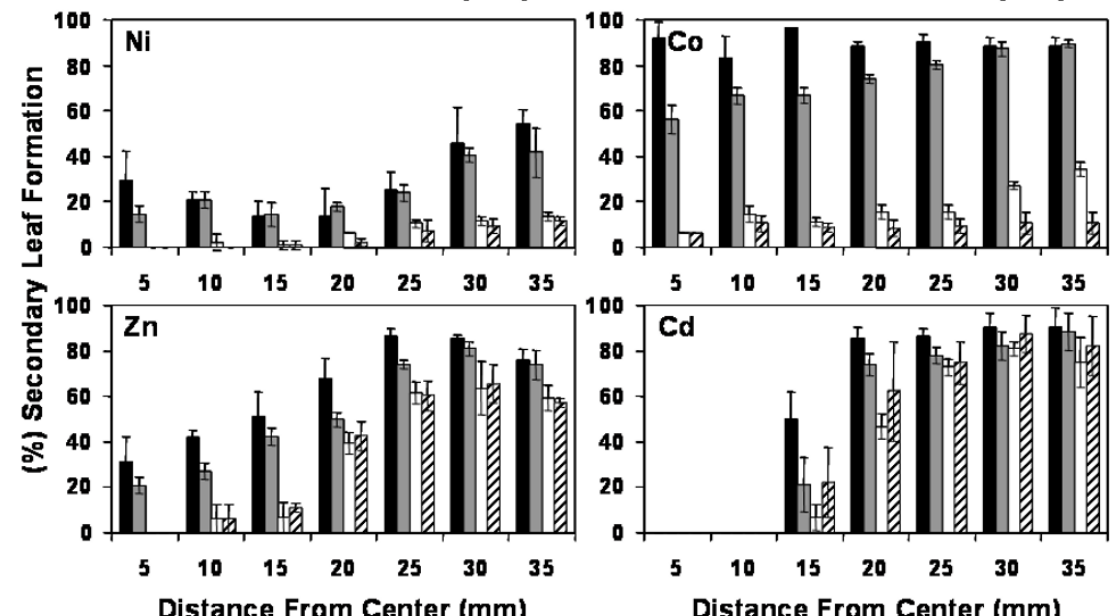

C

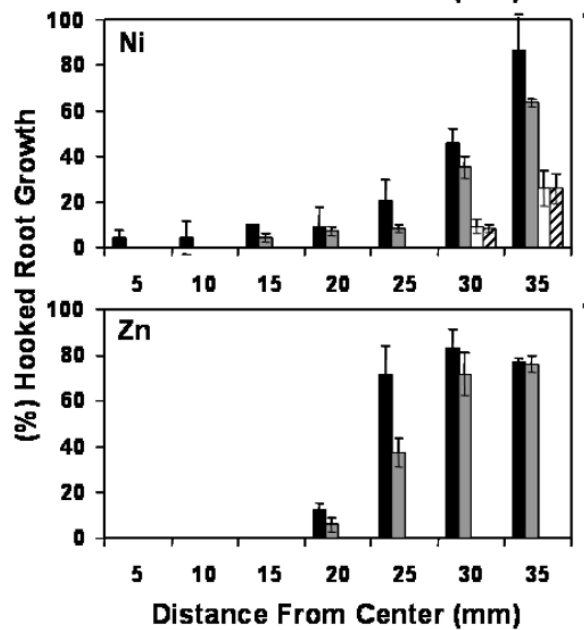

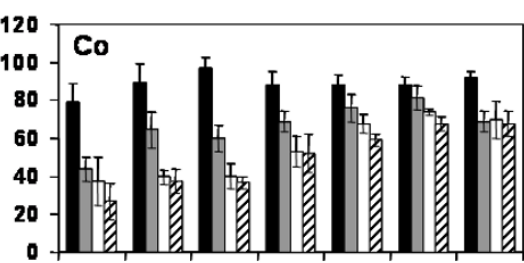
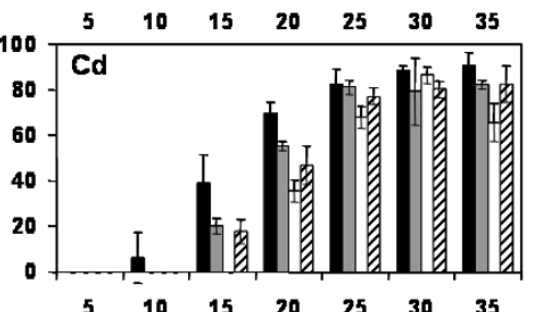

$\begin{array}{llllll}10 & 15 & 20 & 25 & 30 & 35\end{array}$

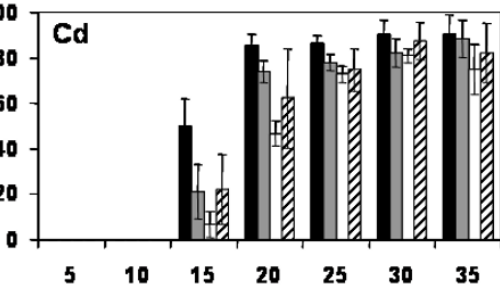

Distance From Center (mm)
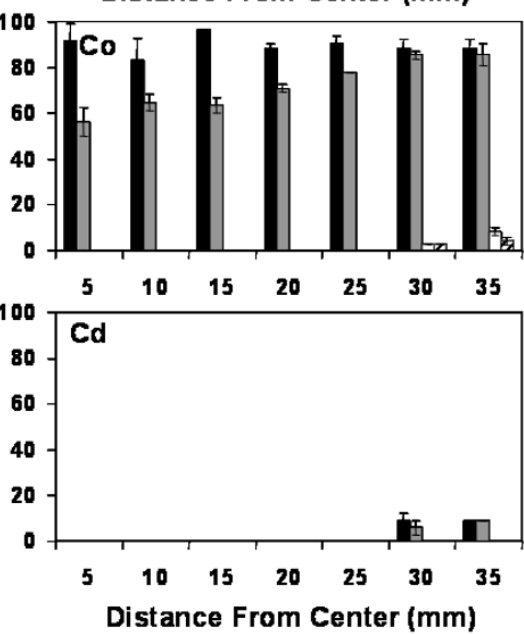

Figure 4

Metal tolerance caused by heterologous expression of TgSATm in A. thaliana. Independent homozygous T4 lines transformed with TgSAT-m [S 4-9 (black), S 3-I (grey) and S 5-4 (white)], representing high, intermediate and low expressers or empty vector E I-5 (striped). Seedlings in each ring around a central filter paper disc soaked with $100 \mu \mathrm{L}$ of $100 \mathrm{mM} \mathrm{Ni}\left(\mathrm{NO}_{3}\right)_{2}, 100 \mathrm{mM}$ Co $\left(\mathrm{NO}_{3}\right)_{2}, 400 \mathrm{mM} \mathrm{Zn}\left(\mathrm{NO}_{3}\right)_{2}$ and $50 \mathrm{mM} \mathrm{Cd}\left(\mathrm{NO}_{3}\right)_{2}$, were scored for upright cotyledons $(\mathbf{A})$, development of secondary leaves (B) or the development of a root hook $(\mathbf{C})$. Seedlings were germinated and grown for 13 days on the assay plates before being scored. Data represent the mean of three replicate assay plates per line \pm SD. 


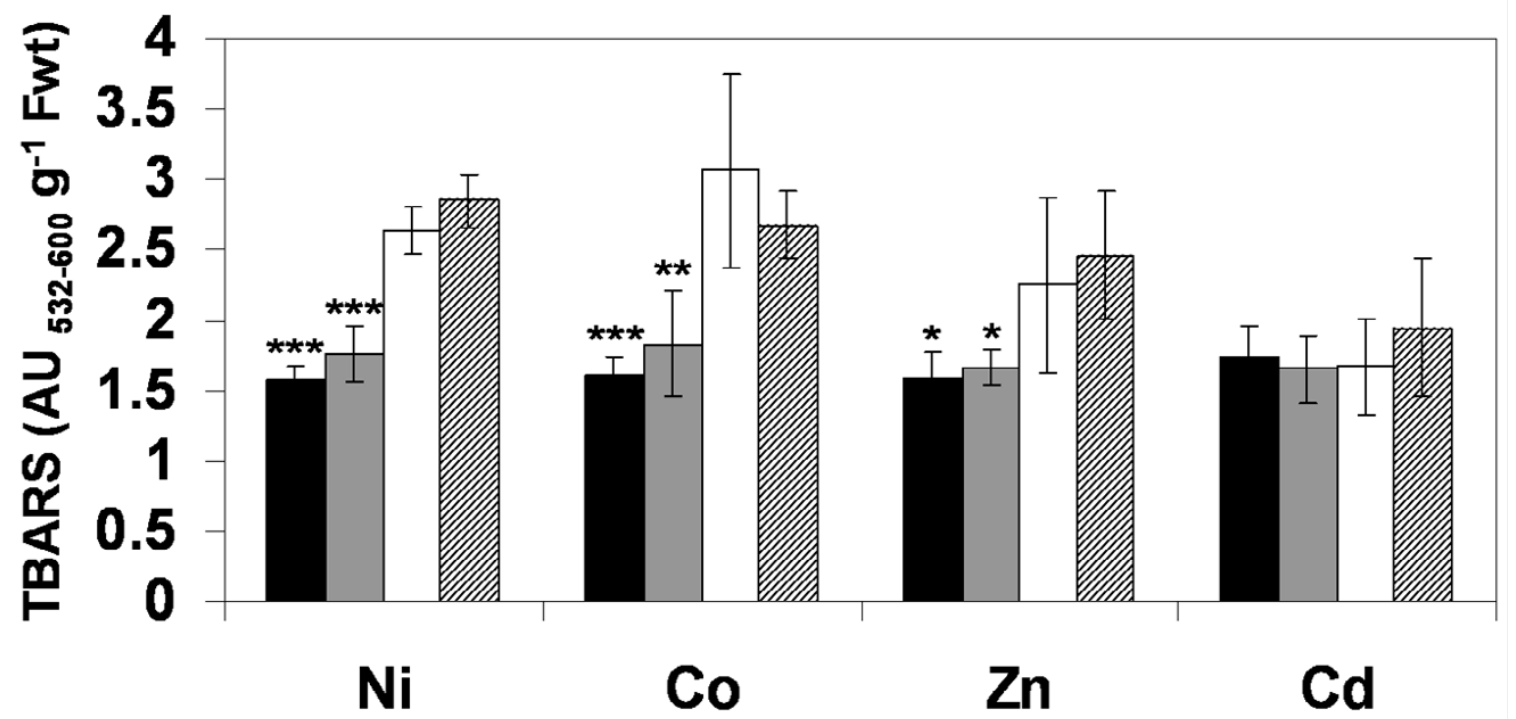

\section{Figure 5}

Effect of heterologous TgSATm expression on oxidative stress induced by different metals in $A$. thaliana shoot tissues from independent homozygous T4 lines transformed with vector containing TgSAT-m, S 4-9(black), S 3-I (grey) and S 5-4(white) or empty vector E I-5(striped). Total shoot lipid peroxidation was measured as TBARS formed in response to each of the 4 different metal treatments after growth in normal media followed by transfer into I/2 strength MS medium plates also containing I $25 \mu \mathrm{M} \mathrm{Ni}\left(\mathrm{NO}_{3}\right)_{2}, I 25 \mu \mathrm{M}$ Co $\left(\mathrm{NO}_{3}\right)_{2}, 125 \mu \mathrm{M} \mathrm{Zn}\left(\mathrm{NO}_{3}\right)_{2}$, and $75 \mu \mathrm{M} \mathrm{Cd}\left(\mathrm{NO}_{3}\right)_{2}$ for a period of 4 days. Values represent difference in TBARS compared to growth on control media without metals. Data represents averages $(n=6) \pm S D(* p<0.05$; $* *$ $\mathrm{p}<0.01 ;{ }^{* * *} \mathrm{p}<0.00 \mathrm{I}$, t-test).

Ni tolerance to A. thaliana [19], and because of its high sequence similarity $(95.0 \%$ identity) to the $A$. thaliana mitochondrial homolog At3g13110 [19]. Additionally, in E. coli, TgSATm conferred enhanced resistance to Ni [30], which was originally used to clone the three different SAT cDNAs from T. goesingense [19]. Furthermore, overexpression of the cytoplasmic, mitochondrial, or chloroplastic SAT from $T$. goesingense or the chloroplastic SAT from A. thaliana in E. coli all conferred approximately equal tolerance to $\mathrm{Ni}$ and $\mathrm{Co}[30]$. The mitochondrial isoform of SAT (TgSAT-m) was also chosen for overexpression in this study because overexpression of the Cys-insensitive $A$. thaliana homolog AtSAT-m (SAT A) had been shown to achieve significant elevations in Cys and GSH concentrations, when overexpressed in tobacco and targeted to either the plastid or the cytosol [21]. In addition to making more OAS, Cys and GSH in the mitochondria, which can then be exported into the cytosol and other organelles, over-expression of TgSATm in the mitochondria could lower Ni induced ROS formation, so the electron transport chain can still provide cells with the energy needed to function.

The hyperaccumulator $T$. goesingense has significant tolerance to the growth inhibitory effects of elevated $\mathrm{Ni}, \mathrm{Zn}$ and Co, with a slight resistance to Cd (Fig. 1 and Table 1), and in part this appears due to an enhanced ability to resist the oxidizing effects of $\mathrm{Ni}, \mathrm{Zn}$ and $\mathrm{Co}$ (Fig 2). The elevated levels of GSH in T. goesingense are thought to contribute to the Ni tolerance of this plant, via enhancing resistance to the oxidizing effects of this metal [19]. We hypothesize that this elevated GSH also causes the elevated tolerance to Co and $\mathrm{Zn}$, but only low level resistance to $\mathrm{Cd}$. To address this question we utilized transgenic $A$. thaliana heterologously expressing $T g S A T_{m}$ that had previously been characterized to contain elevated shoot concentrations of GSH that confer enhanced resistance to $\mathrm{Ni}$ [19].

In addition to $\mathrm{Ni}$ our analysis of the metal tolerance of these same plants showed them to also have tolerance to growth in the presence of elevated Co and $\mathrm{Zn}$ while causing a low level of resistance to $\mathrm{Cd}$, when compared to the control lines (Fig. 3 \&4). Interestingly, the high and intermediate TgSATm expressing lines were found to accumulate $~ 1.4$ fold more $\mathrm{Zn}$ when compared to the low and non-expressing lines. This suggests that increasing GSH and thus $\mathrm{Zn}$ tolerance might positively influence the $\mathrm{Zn}$ accumulation mechanisms in plants.

Furthermore, these transgenic plants also showed increased resistance to the lipid peroxidizing effects of Co 


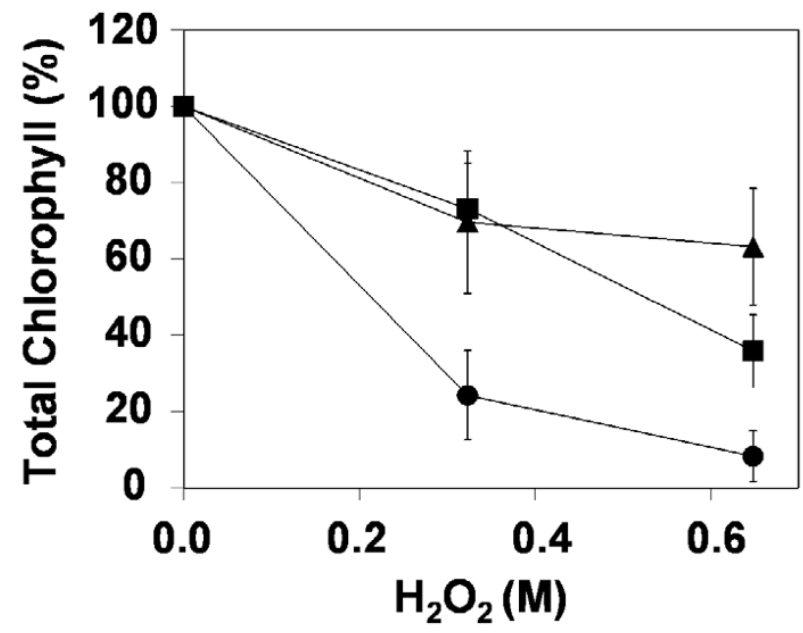

Figure 6

Oxidative stress resistance measured as total chlorophyll content in leaf discs of $T$. goesingense (squares), $A$. thaliana heterologously expressing TgSATm (triangles) and empty vector control $A$. thaliana (circles) after 24 hours flotation on hydrogen peroxide under high light. Data represents averages $(\mathrm{n}=9$ If discs, 3 discs per plant, $\mathrm{n}=3$ plants $) \pm$ SD.

and $\mathrm{Zn}$ (Fig. 5), suggesting that at least one of the roles of GSH in this enhanced Co and Zn resistance is as an antioxidant. These results mirror those previously observed for Ni [19]. However, the elevated GSH concentration in these lines had no effect on levels of lipid peroxidation in plants grown in the presence of Cd, suggesting that GSH is conferring enhanced tolerance to Cd via an unknown alternative pathway potentially through an increased ability to synthesize phytochelatins (PC). Cd resistance was quite low considering that both $T$. goesingense and the TgSATm could tolerate growth on plates containing at least 4 times higher concentrations of $\mathrm{Ni}$, Co and $\mathrm{Zn}$ compared to Cd.

Our results establish that heterologous expression of $\mathrm{TgSAT}_{m}$ also enhances tolerance to other oxidative stresses caused by hydrogen peroxide and high light treatment (Fig. 6). The hyperaccumulator T. goesingense, which is known to have constitutively elevated SAT activity and accumulate, elevated GSH [19], also shows high tolerance to hydrogen peroxide treatment (Fig. 6).

Analysis of the ability of GSH to confer metal tolerance in these transgenic lines also revealed that in shoots GSH is most effective at conferring tolerance to $\mathrm{Ni}=\mathrm{Co}>\mathrm{Zn}>\mathrm{Cd}$ (Fig. 7A). This activity closely follows the levels of lipid peroxidation produced by growth on these three metals (Fig. 5). GSH production was least effective at conferring tolerance to Cd (Fig. 7A), which was exemplified by the no reduction in lipid peroxidation after Cd treatment (Fig.
5). In roots $\mathrm{GSH}$ conferred tolerance to $\mathrm{Co}>\mathrm{Ni}=\mathrm{Zn}>\mathrm{Cd}$ (Fig. 7B).

In both $T$. goesingense and the TgSATm transgenics, SAT enhanced $\mathrm{Ni}$, resistance appears not to involve coordination by PC. This is fully supported by a complete lack of thiol coordination to $\mathrm{Ni}$ in these plants [19,31] and also in E. coli heterologously expressing the same gene [30]. Additionally, $\mathrm{Zn}$ is also not coordinated by $\mathrm{PC}$ or thiols in the $\mathrm{Zn}$ tolerant hyperaccumulator $T$. caerulescens [32]. It has also been determined genetically in the A. thaliana PCS null mutant cad1, which has no measurable PC, that $\mathrm{PC}$ are not involved in either $\mathrm{Ni}$ or $\mathrm{Zn}$ resistance in $\mathrm{A}$. thaliana but are directly needed for Cd resistance [33-36]. While PC are clearly not involved in resistance to $\mathrm{Ni}$ and $\mathrm{Zn}$ in A. thaliana, Co also failed to activate A. thaliana PC synthesis in assays of purified AtPCS1 activity [37]. Therefore Given the chemical similarity between $\mathrm{Ni}$ and Co we can speculate that the enhanced Co resistance observed in the transgenic plants is due to the direct antioxidant effect of increased GSH.

Our findings establish a strong connection between elevated shoot GSH and enhanced tolerance to the lipid peroxidizing effects of $\mathrm{Ni}=\mathrm{Co}>\mathrm{Zn}$ in both $T$. goesingense and transgenic $A$. thaliana containing elevated GSH concentrations. Such a link is supported by the observation that elevated GSH levels in both transgenic A. thaliana and $T$. goesingense correlate with enhanced resistance to the peroxidizing effects caused by hydrogen peroxide and high light treatments.

\section{Conclusion}

We therefore conclude that the multiple metal tolerances to $\mathrm{Ni}$, Co and $\mathrm{Zn}$ observed in T. goesingense are due to the constitutively elevated shoot GSH levels observed in this hyperaccumulator. These multiple metal tolerances are mimicked in Arabidopsis through heterologous expression of the TgSATm gene which results in elevated GSH accumulation in leaves and enhanced oxidative stress resistance.

\section{Methods \\ Plant plate growth}

Plants were germinated and grown on plates containing $1 / 2$ strength MS + Gamborgs B5 medium in $0.8 \%$ plant tissue grade agar alone or with the different metals under $16 \mathrm{hr}$ white light $\left(120 \mu \mathrm{mol} \mathrm{m} \mathrm{m}^{-2} \mathrm{~s}^{-1}\right.$ of photosynthetic photon flux (PPF)). ICP-MS analysis of the different metal levels was performed on all dried shoot tissue as previously described (Lahner et al., 2003).

\section{Metal tolerance assays}

Metal resistance in $A$. thaliana was tested on agar plates $(100 \times 25 \mathrm{~mm})$ containing $1 / 2$ strength $\mathrm{MS}+$ Gamborgs 


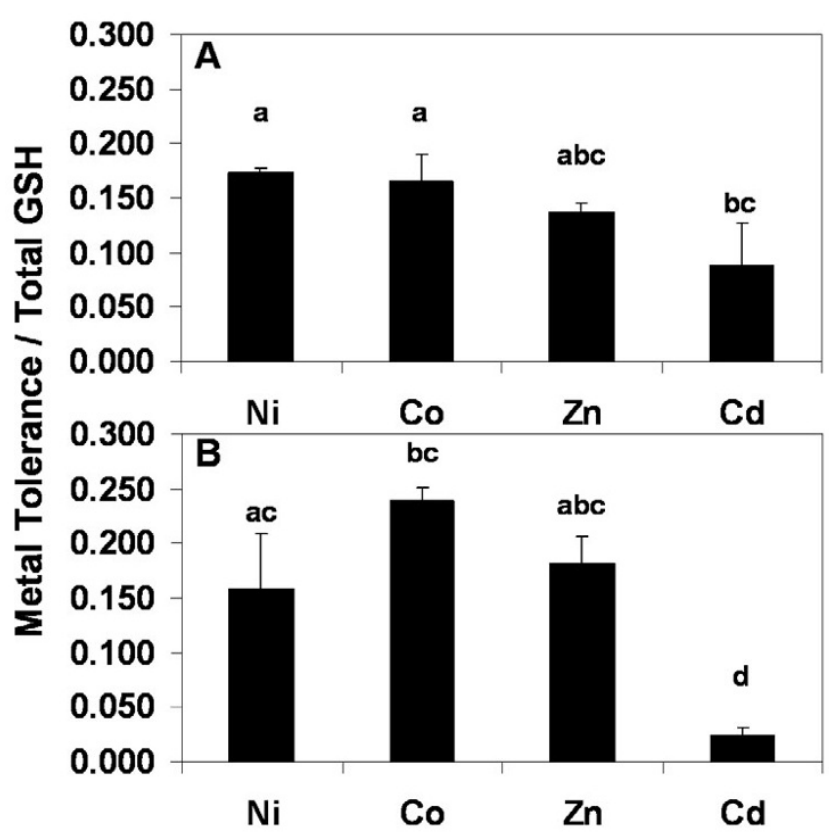

Figure 7

Bar graph showing the slopes of trend lines obtained through plotting metal tolerance to $\mathrm{Ni}, \mathrm{Co}, \mathrm{Zn}$ and $\mathrm{Cd}$ for each line against shoot GSH accumulation. Metal tolerance was scored as the percentage of seedlings with normal upright cotyledons $(\mathbf{A})$ or the formation of a root hook $(\mathbf{B})$. Data represent means of slopes ( $n=3$ for each metal \pm SD). Lower case letters ( $a, b, c$ and $d$ ) represent significantly different means, using the Tukey-Kramer test comparing all pairs $(P<0.05)$. Fits of the metal tolerance verses GSH plots for $\mathrm{Ni}, \mathrm{Co}, \mathrm{Zn}$ and $C d$ in shoots, $R^{2}=0.99,0.96,0.98$, and 0.99 , respectively, and for roots $R^{2}=1.0,1.0,0.98$ and I.0.

B5 medium in $0.8 \%$ plant tissue grade agar. Seeds from $A$. thaliana heterologously expressing $\mathrm{T}$. goesingense $\mathrm{SATm}$ and empty vector control lines were spotted in concentric rings radiating from the center of the plate where a filter paper disc was placed. Onto the disc $100 \mu \mathrm{L}$ of $100 \mathrm{mM}$ $\mathrm{Ni}\left(\mathrm{NO}_{3}\right)_{2}, 100 \mathrm{mM} \mathrm{Co}\left(\mathrm{NO}_{3}\right)_{2}, 400 \mathrm{mM} \mathrm{Zn}\left(\mathrm{NO}_{3}\right)_{2}$ or 50 $\mathrm{mM} \mathrm{Cd}\left(\mathrm{NO}_{3}\right)_{2}$ was pipetted and the plates incubated at $24^{\circ} \mathrm{C} / 20^{\circ} \mathrm{C}, 10 \mathrm{~h} / 14 \mathrm{~h}$ light/dark, $120 \mu \mathrm{mol} \mathrm{m}^{-2} \mathrm{~s}^{-1} \mathrm{PPF}$. After 13 days growth from imbibition the percentage of upright seedlings with fully expanded cotyledons, secondary leaves and hooked roots were recorded for each ring along with the distance in $\mathrm{mm}$ from the metal soaked filter disc. Seedlings from both 20 and $35 \mathrm{~mm}$ rings were then harvested for ICP-MS analysis of metal levels. Metal analysis was performed on dried shoot tissue as previously described [38].

\section{Hydrogen peroxide treatments}

Hydrogen peroxide treatments involved cutting $1 \mathrm{~cm}$ diameter leaf discs from the center of intact mature leaves.
Discs were floated on either $\mathrm{H}_{2} \mathrm{O}_{2}$ or water for $24 \mathrm{~h}$ at $24^{\circ} \mathrm{C}$ in constant light $\left(180 \mu \mathrm{mol} \mathrm{m}{ }^{-2} \mathrm{~s}^{-1} \mathrm{PPF}\right)$. Percent total chlorophyll was measured at $654 \mathrm{~nm}$ following extraction in 96\% ethanol [39], and normalized to chlorophyll observed in the water treated tissue. The chlorophyll contents for the control $\left(\mathrm{H}_{2} \mathrm{O}\right)$ treatments were approximately the same per gram fresh weight for all plants used. Total Chlorophyll $\mathrm{mg} \mathrm{g}^{-1} \mathrm{fwt}$; $T$. goesingense $=$ $1.55 \pm 0.32$, A. thaliana $=1.57 \pm 0.13$, Transgenic TgSATm $=1.58 \pm 0.13$.

\section{Quantification of total lipid peroxidation}

Peroxidized lipids were assayed as the presence of thiobarbituric acid reactive species (TBARS). Plants were grown for 17 days under $16 \mathrm{hr}$ white light $\left(120 \mu \mathrm{mol} \mathrm{m}^{-2} \mathrm{~s}^{-1} \mathrm{PPF}\right)$ on vertical agar plates containing $1 / 2$ strength MS + Gamborgs $\mathrm{B} 5$ medium in $0.8 \%$ plant tissue grade agar. After 4 or 8 days transfer to $1 / 2$ strength MS + Gamborgs B5 medium in $0.8 \%$ plant tissue grade agar plates, containing either $\mathrm{Ni}, \mathrm{Co}, \mathrm{Zn}$ or $\mathrm{Cd}$, shoot tissue was harvested and assayed for TBARS as described previously [40]. During the period of metal exposure all plants remained viable and continued growing

\section{Root length inhibition}

T. goesingense and A. thaliana plants were germinated and grown on vertical plates containing $1 / 2$ strength $\mathrm{MS}+$ Gamborgs B5 medium in 0.8\% agar with various concentrations of $\mathrm{Ni}, \mathrm{Co}, \mathrm{Zn}$ and $\mathrm{Cd}$ for 18 days under $16 \mathrm{hr}$ white light $\left(120 \mu \mathrm{mol} \mathrm{m}^{-2} \mathrm{~s}^{-1} \mathrm{PPF}\right)$. The $\left(\mathrm{I}^{50}\right)$ values were calculated by taking the metal concentrations in plates which caused 50\% inhibition of root growth for the different metals used on both $T$. goesingense and A. thaliana. The maximum normal root growth was measured on the control plates for this experiment in the absence of any metal.

\section{Authors' contributions}

DES conceived the experiments with major contributions from JLF. JLF wrote the paper with major contributions from DES. JLF was primarily responsible for carrying out the experiments. All authors have read and approved the final manuscript.

\section{Acknowledgements}

1 This work was supported by the U.S. National Science Foundation (grant nos. 0I963 I0-IBN and 0I29747-IBN to D.E.S.) and by the Indiana 2 I st Century Research and Technology Fund. Special thanks to the Purdue lonomics Center, especially Brett Lahner for inductively coupled plasma analyses.

\section{References}

I. Baker AJM: Metal Tolerance. New Phytol 1987, 106:93-I II.

2. Bradshaw AD, McNeilly T, Putwain PD: The essential qualities. In Heavy metal tolerance in plants: evolutionary aspects Edited by: Shaw AJ. CRC Press Inc. Boca Raton; 1989:324-334.

3. Clemens S: Molecular mechanisms of plant metal tolerance and homeostasis. Planta 200I, 2 I 2:475-486. 
4. Meharg AA: Mechanisms of plant resistance to metal and metalloid ions and potential biotechnological applications. Plant and Soil 2004, 0: I-I I.

5. Baker AJM, Reeves RD, Hajar SM: Heavy metal accumulation and tolerance in British populations of the metallophyte Thlaspi caerulescens J. \& C. Presl (Brassicaceae). New Phytol 1994, I 27:61-68.

6. Persans MW, Salt DE: Possible molecular mechanisms involved in nickel, zinc and selenium hyperaccumulation in plants. Biotechnol Genet Eng Rev 2000, 17:389-4I3

7. Salt DE, Kramer U: Mechanisms of Metal Hyperaccumulation in Plants. In Phytoremediation of Toxic Metals Edited by: Raskin I, Ensley BD. John Wiley and Sons Inc; 2000:23I-246.

8. Macnair MR, Bert V, Huitson SB, Saumitou-Laprade P, Petit D: Zinc tolerance and hyperaccumulation are genetically independent characters. Proc R Soc Lond Biol Sci 1999, 266:2175-2179.

9. Assuncao AGL, Ten Bookum WM, Nelissen JM, Vooijs R, Schat H, Ernst WHO: A cosegregation analysis of zinc ( $\mathbf{Z n})$ accumulation and $\mathbf{Z n}$ tolerance in the $Z n$ hyperaccumulator Thlaspi caerulescens. New Phytol 2003, I 59:45-56.

10. Becher M, Talke IN, Krall L, Krämer U: Cross-species microarray transcript profiling reveals high constituative expression of metal homeostasis genes in shoots of the zinc hyperaccumulator Arabidopsis halleri. Plant J 2004, 37:25 I-268.

II. Weber M, Harada E, Vess C, Roepenack-Lahaye EV, Clemens S: Comparative microarray analysis of Arabidopsis thaliana and Arabidopsis halleri roots identifies nicotianamine synthase, a ZIP transporter and other genes as potential metal hyperaccumulation factors. Plant / 2004, 37:269-28I.

12. Hammond JP, Bowen HC, White PJ, Mills V, Pyke KA, Baker AJM, Whiting SN, May ST, Broadley A, Martin R: A comparison of the Thlaspi caerulescens and Thlaspi arvense shoot transcriptomes. New Phytol 2006, I 70:239-260.

13. Baccouch S, Chaoui A, El Ferjani E: Nickel-induced oxidative damage and antioxidant responses in Zea mays shoots. Plant Physiol Biochem 1998, 36:689-694.

14. Briat JF, Lebrun M: Plant responses to metal toxicity. C R Acad Sci III 1999, 322:43-54.

15. Dat J, Vandenabeele S, Vranova E, Van Montagu M, Inze D, Van Breusegem F: Review, Dual action of the active oxygen species during plant stress responses. Cell Mol Life Sci 2000, 57:779-795.

16. Noctor G, Foyer CH: Ascorbate and Glutathione: Keeping Active Oxygen Under Control. Annu Rev Plant Physiol Plant Mol Biol 1998, 49:249-279.

17. Schutzendubel A, Polle A: Plant responses to abiotic stresses: heavy metal-induced oxidative stress and protection by mycorrhization. J Exp Bot 2002, 53:135|-1365.

18. Noctor G, Strohm M, Jouanin L, Kunert KJ, Foyer CH, Rennenber $\mathrm{H}$ : Synthesis of Glutathione in Leaves of Transgenic Poplar Overexpressing [gamma]-Glutamylcysteine Synthetase. Plant Physiol 1996, I I 2: I07|-1078.

19. Freeman JL, Persans MW, Nieman K, Albrecht C, Peer W, Pickering I], Salt DE: Increased glutathione biosynthesis plays a role in nickel tolerance in Thlaspi nickel hyperaccumulators. Plant Cell 2004, I 6:2176-2191

20. Peer WA, Mahmoudian M, Freeman JL, Lahner B, Richards EL, Reeves RD, Murphy AS, Salt DE: Assessment of Plants from the Brassicaceae Family as Genetic Models for the Study of Nickel and Zinc Hyperaccumulation. New Phytologist 2006, I 72:248-260.

21. Wirtz M, Hell R: Production of cysteine for bacterial and plant biotechnology application of cysteine feedback-insensitive isoforms of serine acetyltransferase. Amino Acids 2003, 24:195-203.

22. Barroso C, Vega JM, Gotor C: A new member of the cytosolic O-acetylserine(thiol)lyase gene family in Arabidopsis thaliana. FEBS Lett 1995, 363:1-5.

23. Meyer AJ, Fricker MD: Control of demand-driven biosynthesis of glutathione in green Arabidopsis suspension culture cells. Plant Physiol 2002, 130:1927-1937.

24. Xiang C, Oliver DJ: Glutathione metabolic genes coordinately respond to heavy metals and jasmonic acid in Arabidopsis. Plant Cell 1998, 10:1539-1550.

25. Howarth JR, Dominguez-Solis JR, Gutierrez-Alcala G, Wray JL, Romero LC, Gotor C: The serine acetyltransferase gene family in Arabidopsis thaliana and the regulation of its expression by cadmium. Plant Mol Biol 2003, 5 I:589-598.
26. Blasczyk A, Brodzik R, Sirko A: Increased resistance to oxidative stress in transgenic tobacco plants over expressing bacterial serine acetyltransferase. Plant J 1999, 20:237-243.

27. Foyer $\mathrm{CH}$, Souriau N, Perret S, Lelandais M, Kunert KJ, Pruvost C Jouanin L: Overexpression of glutathione reductase but not glutathione synthetase leads to increases in antioxidant capacity and resistance to photoinhibition in poplar trees. Plant Physiol 1995, 109:1047-1057.

28. Youssefian S, Nakamura $M$, Orudgev E, Kondo N: Increased cysteine biosynthesis capacity of transgenic tobacco overexpressing an O-acetylserine(thiol) lyase modifies plant responses to oxidative stress. Plant Physiol 200 I, 126:100 I-10 I I.

29. Zhu YL, Pilon-Smits EA, Tarun AS, Weber SU, Jouanin L, Terry N: Cadmium tolerance and accumulation in Indian mustard is enhanced by overexpressing gamma-glutamylcysteine synthetase. Plant Physiol 1999, I 2 I: I I69- I I 78.

30. Freeman JL, Persans MW, Nieman K, Salt DE: Nickel and Cobalt Resistance Engineered in Escherichia coli by Overexpression of Serine Acetyltransferase from the Nickel Hyperaccumulator Plant Thlaspi goesingense. Applied and Environmental Microbiology 2005, 7 I:8627-8633.

31. Kramer U, Pickering IJ, Prince RC, Raskin I, Salt DE: Subcellular localization and speciation of nickel in hyperaccumulator and non-accumulator Thlaspi species. Plant Physiol 2000, I 22: 1343-1353.

32. Salt DE, Prince RC, Baker AJM, Raskin I, Pickering IJ: Zinc ligands in the metal hyperaccumulator Thlaspi caerulescens as determined using X-ray absorption spectroscopy. Env Sci Tech 1999, 33:7|3-7|7.

33. Howden R, Cobbett CS: Cadmium-Sensitive Mutants of Arabidopsis thaliana. Plant Physiol 1992, I00(I): I00-107.

34. Howden R, Goldsbrough PB, Andersen CR, Cobbett CS: Cadmiumsensitive, cad I mutants of Arabidopsis thaliana are phytochelatin deficient. Plant Physiol 1995, I07: I059-1066.

35. Ha S-B, Smith AP, Howden R, Dietrich WM, Bugg S, O'Connell MJ, Goldsbrough PB, Cobbett CS: Phytochelatin synthase genes from Arabidopsis and the yeast Schizosaccharomyces pombe. Plant Cell I999, I I: I I53-I I63.

36. Cobbett CS: Phytochelatins and their role in heavy metal detoxification. Plant Physiol 2000, I 23:825-832.

37. Vatamaniuk OK, Mari S, Lu Y-P, Rea PA: Mechanism of heavy metal ion activation of phytochelatin (PC) synthase. J Biol Chem 2000, 275:3|45|-3|459.

38. Lahner B, Gong J, Mahmoudian M, Smith EL, Abid KB, Rogers EE, Guerinot ML, Harper JF, Ward JM, Mclntyre L, Schroeder JI, Salt DE: Genomic scale profiling of nutrient and trace elements in Arabidopsis thaliana. Nat Biotechnol 2003, 21:1215-1221.

39. Wintermans JFGM, De Mots A: Spectrophotometric Characteristics of Chlorophylls $a$ and $b$ and their Pheophytins in Ethanol. Biochim Biophys Acta 1965, 109:448-453.

40. Murphy AS, Eisinger WR, Shaff JE, Kochian LV, Taiz L: Early copperinduced leakage of $\mathrm{K}^{+}$from Arabidopsis seedlings is mediated by ion channels and coupled to citrate efflux. Plant Physio 1999, | $21: 1375-1382$.

Publish with Bio Med Central and every scientist can read your work free of charge

"BioMed Central will be the most significant development for disseminating the results of biomedical research in our lifetime. "

Sir Paul Nurse, Cancer Research UK

Your research papers will be:

- available free of charge to the entire biomedical community

- peer reviewed and published immediately upon acceptance

- cited in PubMed and archived on PubMed Central

- yours - you keep the copyright
BioMedcentral 